\title{
How Much Have U.S. House Prices Fallen?
}

\author{
Craig P. Aubuchon and David C. Wheelock
}

$\mathrm{H}$ ouse prices in the United States were 14.1 percent lower in the first quarter of 2008 than they were a year earlier, according to a widely cited measure of U.S. house prices, the S\&P/Case-Shiller (S\&P/CS) National Home Price Index. However, another widely cited measure, the Office of Federal Housing Enterprise Oversight (OFHEO) house price index, based solely on purchases, indicated house prices were down a mere 3.1 percent. Still other measures indicate different declines in U.S. house prices, although most lie between the S\&P/CS and OFHEO indices.

Measures of U.S. house prices are constructed using a variety of data and methods, which explains the reported differences. The S\&P/CS and the OFHEO indices are "repeat sales" indices, which control for changes in the average quality of houses over time by tracking changes in the prices of houses sold more than once. Both indices also are designed to show nationwide house price trends. Nevertheless, as the chart shows, the two indices have diverged widely over the past decade. The S\&P/CS index indicated a more rapid rise in U.S. house prices during 1998-2006 than did the OFHEO index; it also showed a more rapid decline in house prices during 2007-08.

The OFHEO index tracks the sales prices of houses financed with conforming, conventional mortgages purchased by Fannie Mae and Freddie Mac. In 2007, conforming loans were limited to a maximum of $\$ 417,000$. Home purchases involving larger, "jumbo" mortgages, or unconventional mortgages-including many subprime mortgages-do not influence the OFHEO index. By contrast, the S\&P/CS index is based on transaction information reported by county assessors and recorder offices; it includes data on houses financed by jumbo mortgages, subprime mortgages, and home purchases that do not involve a mortgage.

The S\&P/CS index is also value weighted: More expensive homes have relatively greater influence on the index, whereas the OFHEO index is unit weighted. Furthermore, the $\mathrm{S} \& \mathrm{P} / \mathrm{CS}$ index assigns greater weight to census regions with greater total residential real estate value. The OFHEO index, by contrast, weights regions based on the number of residential units. Hence, regions with relatively higher average home prices have more influence on the S\&P/CS index than on the OFHEO index. ${ }^{1}$

The S\&P/CS index exhibited faster growth in house prices before 2006 because house prices rose more rapidly in the regions with more influence on that index. These regions also tended to have a higher percentage of transactions involving mortgages ineligible for purchase by Fannie Mae and Freddie Mac. The relatively rapid decline in house prices since 2006 in the West and East Coast regions, and the relatively greater weight given these regions in the S\&P/CS index help explain why the S\&P/CS index shows a more rapid decline in house prices for the United States as a whole.

\footnotetext{
${ }^{1}$ Both Standard \& Poor's and OFHEO maintain multiple house price indices, including regional indices, indices for large metropolitan areas, and indices based on different types of house transactions. See www2.standardandpoors.com/ for additional information about S\&P/Case-Shiller Home Price Indices, and www.ofheo.gov/ hpi.aspx for information about home price indices produced by OFHEO.
}

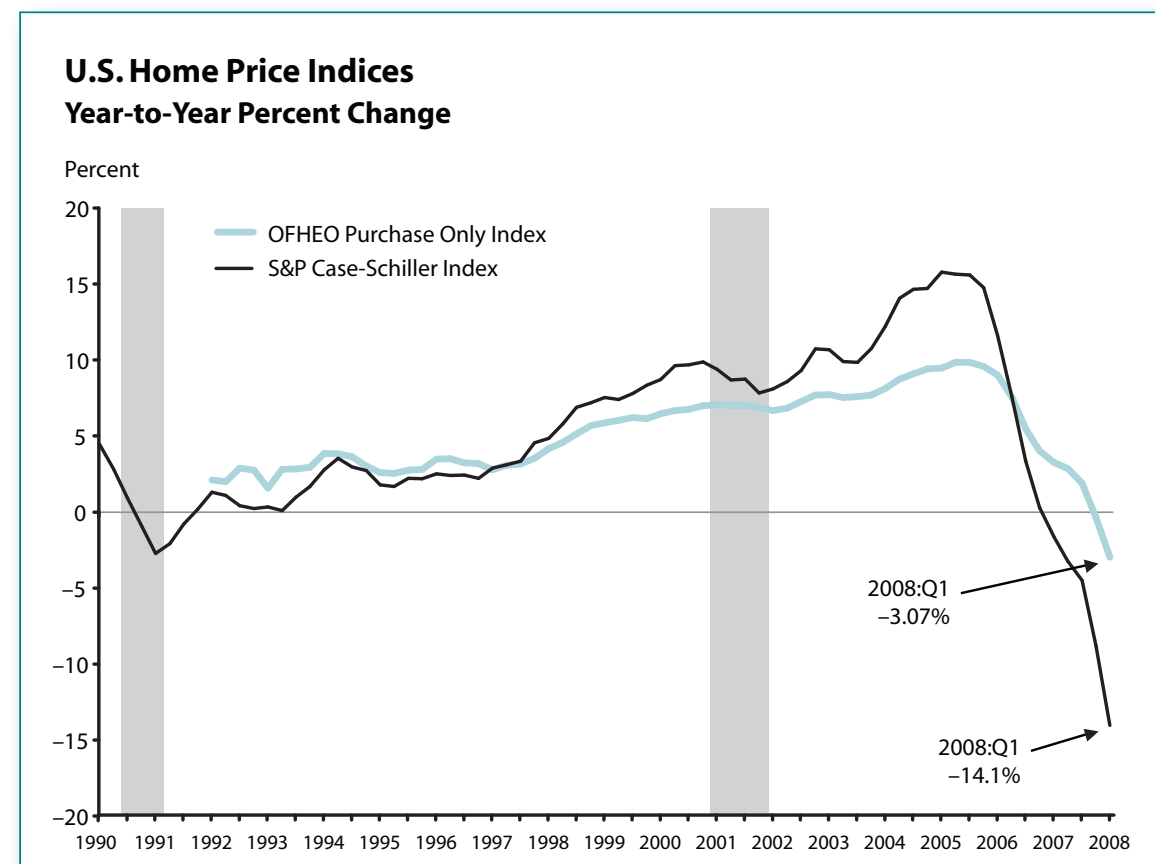

Views expressed do not necessarily reflect official positions of the Federal Reserve System. 